\title{
BMJ Open Vascular endothelial growth factor as a predictive marker for POEMS syndrome treatment response: retrospective cohort study
}

\author{
S Misawa, ${ }^{1}$ Y Sato, ${ }^{2} \mathrm{~K}$ Katayama, ${ }^{2} \mathrm{H}$ Hanaoka, ${ }^{2} \mathrm{~S}$ Sawai, ${ }^{4} \mathrm{M}$ Beppu, ${ }^{4} \mathrm{~F}$ Nomura,${ }^{4}$ \\ K Shibuya, ${ }^{1}$ Y Sekiguchi, ${ }^{1}$ Y Iwai, ${ }^{1} \mathrm{~K}$ Watanabe, ${ }^{1} \mathrm{H}$ Amino, ${ }^{1} \mathrm{C}$ Ohwada, ${ }^{3}$ \\ M Takeuchi, ${ }^{3}$ E Sakaida, ${ }^{3}$ C Nakaseko, ${ }^{3}$ S Kuwabara ${ }^{1}$
}

To cite: Misawa S, Sato $Y$, Katayama K, et al. Vascular endothelial growth factor as a predictive marker for POEMS syndrome treatment response: retrospective cohort study. BMJ Open 2015:5:e009157. doi:10.1136/bmjopen-2015009157

- Prepublication history for this paper is available online. To view these files please visit the journal online (http://dx.doi.org/10.1136/ bmjopen-2015-009157)

Received 22 June 2015 Revised 1 October 2015 Accepted 20 October 2015

CrossMark

\begin{abstract}
${ }^{1}$ Department of Neurology, Graduate School of Medicine, Chiba University, Chiba, Japan

${ }^{2}$ Clinical Research Center, Chiba University Hospital, Chiba, Japan

${ }^{3}$ Department of Hematology, Chiba University Hospital, Chiba, Japan

${ }^{4}$ Department of Molecular Diagnosis, Graduate School of Medicine, Chiba University, Chiba, Japan
\end{abstract}

Correspondence to Dr Sonoko Misawa; sonoko.m@mb.infoweb.ne.jp

\section{ABSTRACT}

Objective: POEMS (polyneuropathy, organomegaly, endocrinopathy, M-protein and skin changes) syndrome is a rare multisystem disease characterised by plasma cell dyscrasia and overproduction of vascular endothelial growth factor (VEGF). VEGF is assumed to be useful in monitoring disease activity, because VEGF levels usually decrease after treatment. However, there is no study to investigate whether the extent of decrease in VEGF correlates with clinical outcome. We tested the predictive efficacy of serum VEGF levels in POEMS syndrome.

Method: This was an institutional review board approved retrospective observational cohort study of 20 patients with POEMS monitored regularly for more than 12 months (median follow-up, 87 months) after treatment onset using our prospectively accumulated database of POEMS from 1999 to 2015. Patients were treated by autologous peripheral blood stem cell transplantation or thalidomide administration. Serum VEGF was measured by ELISA. Outcome measures included clinical and laboratory findings and relapsefree survival.

Results: Serum VEGF levels decreased rapidly after treatment, and stabilised by 6 months post treatment. Patients with normalised serum VEGF levels $(<1040 \mathrm{pg} / \mathrm{mL})$ at 6 months showed prolonged relapsefree survival (HR=12.81, 95\% Cl 2.691 to 90.96 ; $\mathrm{p}=0.0001$ ) and greater later clinical improvement. The rate of serum VEGF reduction over the first 6 months post treatment correlated with increased grip strength, serum albumin levels, and compound muscle action potential amplitudes at 12 months.

Conclusions: Serum VEGF level at 6 months post treatment is a predicative biomarker for disease activity and prognosis in POEMS syndrome. Serum VEGF could be used as a surrogate endpoint for relapse-free survival or clinical or laboratory improvement of POEMS syndrome for clinical trials.

\section{INTRODUCTION}

POEMS (polyneuropathy, organomegaly, endocrinopathy, M-protein and skin changes)

\section{Strengths and limitations of this study}

- This study showed the extent of serum vascular endothelial growth factor (VEGF) reduction after treatment significantly correlates with the prognosis in POEMS (polyneuropathy, organomegaly, endocrinopathy, M-protein, and skin changes) syndrome.

- VEGF can be used as a surrogate marker in prospective clinical trials for POEMS syndrome.

- This is a retrospective study, including a small number of patients of different background and age.

syndrome is a rare (prevalence 0.3 per $100000)$ multisystemic disorder associated with plasma cell dyscrasia. ${ }^{12}$ Potentially fatal clinical manifestations include progressive demyelinating polyneuropathy leading to tetraplegia. ${ }^{3-5}$ Overproduction of vascular endothelial growth factor (VEGF), a multifunctional cytokine that induces angiogenesis and microvascular hyperpermeability, ${ }^{6}$ may be involved in the pathogenesis of many POEMS symptoms. Serum VEGF is markedly and specifically elevated in this syndrome, ${ }^{7-10}$ and major diagnostic criteria include increased VEGF. ${ }^{11-13}$ Moreover, serum VEGF concentration usually decreases following successful therapeutic intervention. ${ }^{14-17}$ However, no study has investigated whether changes in VEGF levels after treatment are predictive of clinical improvement or outcome.

New therapeutic interventions, such as autologous peripheral blood stem cell transplantation and immunomodulatory drug regimens, have improved POEMS prognosis, ${ }^{14} 151819$ but comparative evaluations of treatment efficacy are lacking. Most POEMS studies are retrospective case series or case reports rather than prospective randomised controlled clinical trials due to the rarity of 
this disease. ${ }^{12}$ A reliable early biomarker of long-term outcome could facilitate clinical trials even with a limited patient sample. Therefore, we examined whether VEGF levels are predictive of longer-term clinical improvement.

\section{METHODS}

\section{Subjects}

This observational study was approved by the institutional review board of Chiba University Graduate School of Medicine. The diagnosis of POEMS was established using the published criteria. ${ }^{12}$ Study subjects for this retrospective cohort study were drawn from our database of 85 consecutive patients with POEMS (57 men) treated from 1999 to 2015. From this database, we identified 21 consecutive patients who started primary POEMS syndrome treatment, peripheral blood stem cell transplantation or thalidomide, during the 10-year period 1999-2009 because in 2010 we began an ongoing clinical trial of POEMS syndrome in which serum VEGF levels are blinded.

From the 21 patients, we excluded one patient treated with bevacizumab (anti-VEGF monoclonal antibody) because bevacizumab strongly suppresses VEGF levels for several months. In the 20 patients, VEGF levels were measured regularly (at least once every 3-6 months) for more than 1 year after transplantation or thalidomide treatment and the median follow-up period is 87 months (range 24-133 months). Clinical signs (performance status, overall neuropathy limitation scale and grip strength (sum of both hands)) and blood tests were checked at each visit and nerve conduction studies were performed every 3-6 months. Eight patients were pretreated with low to moderate dose steroids $(n=7)$ or immunoglobulin $(\mathrm{n}=1)$ prior to transplantation or thalidomide. Clinical and laboratory profiles of the 20 patients are shown in table 1 . Changes in serum VEGF levels after treatment were measured and correlations with clinical/laboratory findings, relapse-free survival and complete remission were calculated. We defined relapse as clinical deterioration attributable to POEMS syndrome, such as extravascular overload (oedema/effusions/ascites) or neuropathy, and censoring was defined as the last visit during the observation period. Complete remission was defined according to the International Myeloma Working Group criteria: negative immunofixation with disappearance of any plasma cytomas and $>5 \%$ plasma cells in the bone marrow. ${ }^{17} 20$ One author (SM) selected the patients from the database and reviewed medical records. YS, who was blinded to the clinical information, mainly performed statistical analysis.

\section{Treatments for POEMS syndrome}

Patients were treated with transplantation $(n=12)$ or thalidomide and dexamethasone $(\mathrm{n}=8)$. Autologous peripheral blood stem cell collection was performed after mobilisation by subcutaneous granulocyte colony-stimulating factor with or without high-dose cyclophosphamide $\left(2 \mathrm{~g} / \mathrm{m}^{2} /\right.$ day for 2 consecutive days). High-dose melphalan chemotherapy $\left(140-200 \mathrm{mg} / \mathrm{m}^{2}\right)$ and stem-cell transplantation were performed approximately 1 month after blood cell collection according to the standard treatment regimen for multiple myeloma. Melphalan dose was reduced in patients with performance status 4 (completely disabled). The median follow-up period after transplantation was 90 months (range 35-133 months). Combination thalidomide (100-300 mg/day on days 1-28) and dexamethasone (12 $\mathrm{mg} / \mathrm{m}^{2}$ on days $1-4$ ) was administered every 4 weeks for 19-42 cycles (median 32 cycles). The median follow-up period after thalidomide administration was 87 months (range 24-106 months).

\section{VEGF measurements}

Serum VEGF levels were measured by ELISA commercially (Special Reference Laboratory Co., Tokyo, Japan).

Table 1 Patient characteristics $(n=20)$

\begin{tabular}{|c|c|c|}
\hline & Auto-PBSCT $(n=12)$ & Thalidomide $(n=8)$ \\
\hline \multicolumn{3}{|l|}{ Clinical profiles } \\
\hline Age (years) & $48(36-61)$ & $69(59-84)$ \\
\hline Gender (male:female) & $9: 3$ & $5: 3$ \\
\hline Time from symptoms to therapy (months) & $17(2-120)$ & $25(4-101)$ \\
\hline Performance status & $1(1-4)$ & $2(1-3)$ \\
\hline Overall Neuropathy Limitation Scale & $5(1-11)$ & $6(2-9)$ \\
\hline \multicolumn{3}{|l|}{ Laboratory data } \\
\hline Albumin (g/dL) & $3.8(2.7-4.5)$ & $3.4(2.7-3.9)$ \\
\hline Creatinine $(\mathrm{mg} / \mathrm{dL})$ & $0.7(0.5-1.2)$ & $0.9(0.4-2.0)$ \\
\hline Immunoglobulin (IgA:IgG) & $4: 6$ & $2: 5$ \\
\hline Vascular endothelial growth factor & $2950(126-7870)$ & $2520(1430-7970)$ \\
\hline \multicolumn{3}{|l|}{ Nerve conduction study (median nerve) } \\
\hline CMAP amplitude (mV) & $5.3(0-12.8)$ & $5.2(0.1-9.4)$ \\
\hline Motor conduction velocity $(\mathrm{m} / \mathrm{s})$ & $33.0(23-45)$ & $26(14-48)$ \\
\hline
\end{tabular}

Data are given as median (range).

CMAP, compound muscle action potential; PBSCT, peripheral blood stem cell transplantation. 
The cut-off values for diagnosis of POEMS was established using data from 50 untreated patients with POEMS (33 men; age range 34-76 years) from our retrospective cohort and samples from 120 healthy subjects (61 men; age range 21-79 years). The cut-off value for diagnosis $(1040 \mathrm{pg} / \mathrm{mL})$ was defined as the point with $100 \%$ sensitivity and $99 \%$ specificity by plotting receiver operating characteristic curves.

\section{Statistical analyses}

For the baseline variables, summary statistics were constructed employing frequencies and proportions for categorical data, and means and SDs for continuous variables. Univariate analyses were carried out using the t test or Mann-Whitney $U$ test for continuous variables and Fisher's exact test for categorical variables. For time-to-event outcomes, the Kaplan-Meier method was used to estimate relapse-free survival for each group, and the difference in survival between groups was
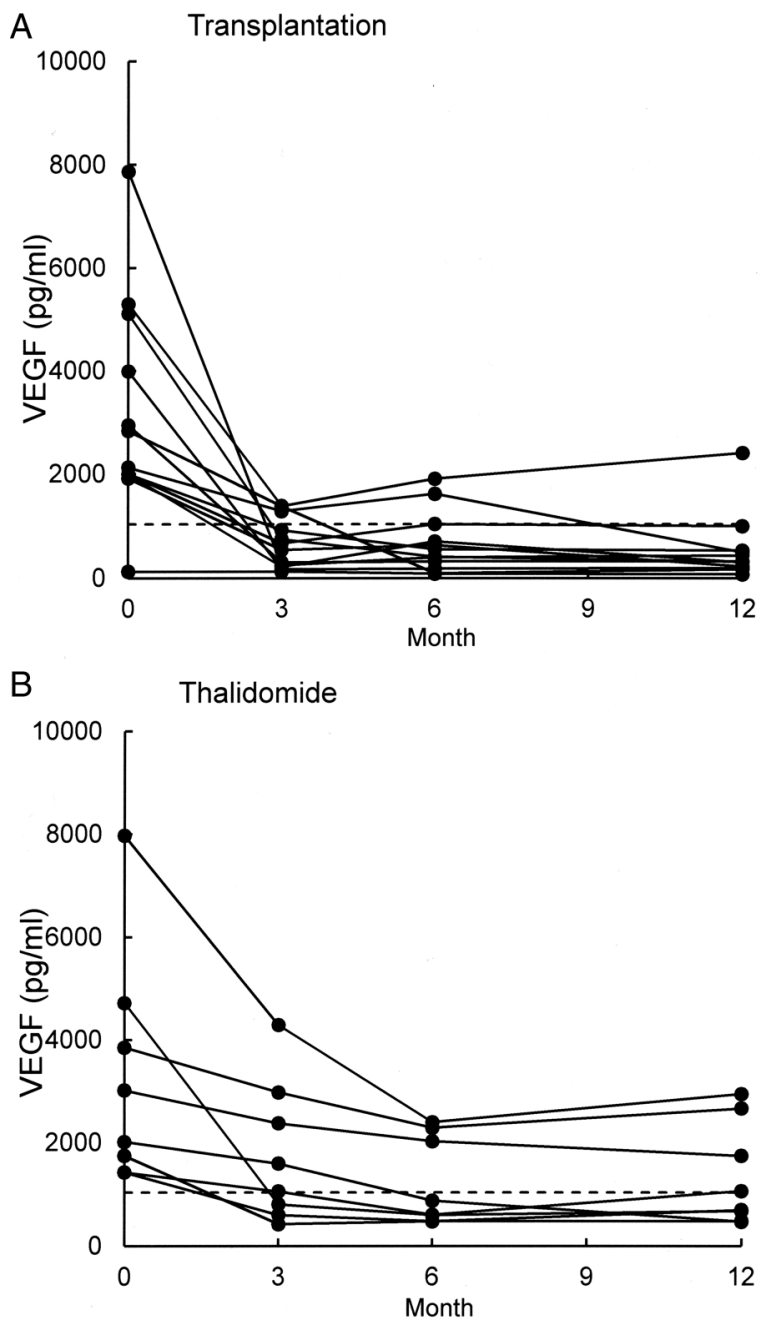

Figure 1 Changes in serum vascular endothelial growth factor (VEGF) after treatment. (A) Autologus peripheral blood stem cell transplantation with high-dose chemotherapy $(n=12)$.

(B) Thalidomide-dexamethasone therapy $(n=8)$. compared by the log-rank test. The HRs and 95\% CIs were estimated by the Cox proportional hazards model.

All comparisons were planned and the tests were two sided. A p value of less than 0.05 was considered to indicate a statistically significant difference. All statistical analyses were conducted using JMP, Japanese V.5.1.1 for Windows (SAS Institute Inc., Cary, North Carolina, USA).

\section{RESULTS}

\section{Changes in VEGF levels after treatment and relapse-free} survival

Before the start of autologous peripheral blood stem cell transplantation or thalidomide treatment for POEMS syndrome, serum VEGF was elevated above the cut-off value $(1040 \mathrm{pg} / \mathrm{mL})$ in all but one patient. The one pretreated for 6 months with moderate-dose steroid (prednisone 20-30 mg daily) exhibited low VEGF levels throughout the study period following primary POEMS syndrome treatment (transplantation). Serum VEGF levels decreased steadily over 6 months after primary treatment and eventually stabilised in all patients (figure 1). Patients treated by transplantation $(n=12)$ had a mean \pm SD baseline VEGF of $3186 \pm 2072 \mathrm{pg} / \mathrm{mL}$, decreasing to $668 \pm 481 \mathrm{pg} / \mathrm{mL}$ at 3 months, $\quad 664 \pm 584 \mathrm{pg} / \mathrm{mL}$ at 6 months, and $541 \pm 635 \mathrm{pg} / \mathrm{mL}$ at 12 months post treatment. The rate of decrease among patients treated with transplantation was steeper than those treated with thalidomide $(3273 \pm 2244 \mathrm{pg} / \mathrm{mL}$ at baseline, $1770 \pm 1352 \mathrm{pg} /$ $\mathrm{mL}$ at 3 months, $1223 \pm 857 \mathrm{pg} / \mathrm{mL}$ at 6 months, and 1350 $\pm 993 \mathrm{pg} / \mathrm{mL}$ at 12 months). All patients with serum VEGF $\geq 1040 \mathrm{pg} / \mathrm{mL}$ (cut-off value) at 6 months post treatment relapsed with a median time of 36 months. The Kaplan-Meier estimates of relapse-free survival at 3 years were $93 \%$ in patients with VEGF levels $<1040 \mathrm{pg} /$ $\mathrm{mL}$ and $40 \%$ in patients with VEGF levels $\geq 1040 \mathrm{pg} / \mathrm{mL}$

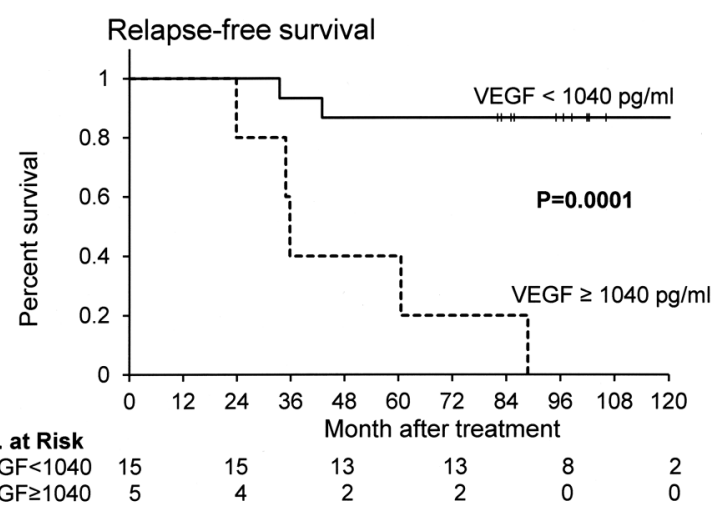

Figure 2 Kaplan-Meier plot for relapse-free survival. Patients with vascular endothelial growth factor (VEGF) $<1040 \mathrm{pg} / \mathrm{mL}$ at 6 months after treatment showed significant longer relapse-free survival than patients with VEGF $\geq 1040 \mathrm{pg} / \mathrm{mL}(\mathrm{HR}=12.81,95 \% \mathrm{Cl} 2.691$ to 90.96 ; $\mathrm{p}=0.0001$ ). 
Table 2 Changes in clinical and laboratory parameters after treatment $(n=20)$

\begin{tabular}{|c|c|c|c|c|c|}
\hline & \multirow{2}{*}{$\begin{array}{l}\text { A } \\
\text { Baseline }\end{array}$} & \multirow{2}{*}{$\begin{array}{l}\text { B } \\
6 \text { months }\end{array}$} & \multirow{2}{*}{$\begin{array}{l}\text { C } \\
12 \text { months }\end{array}$} & \multicolumn{2}{|c|}{ p Value } \\
\hline & & & & A vs B & A vs $C$ \\
\hline Performance status & $1.5(1-4)$ & $1(1-4)$ & $1(1-4)$ & 1.0 & 0.19 \\
\hline \multicolumn{6}{|l|}{ Overall Neuropathy Limitation Scale } \\
\hline Arm scale & $2(0-4)$ & $2(0-4)$ & $1(0-4)$ & 0.069 & 0.0016 \\
\hline Leg scale & $3(1-7)$ & $3(1-7)$ & $2.5(0-7)$ & 0.15 & 0.025 \\
\hline Grip & $28(6-85)$ & $32(0-93)$ & $40(0-107)$ & 0.052 & 0.014 \\
\hline \multicolumn{6}{|l|}{ Laboratory data } \\
\hline Albumin (g/dL) & $3.8(2.7-4.5)$ & $3.55(2.7-4.8)$ & $4.3(2.7-5.1)$ & 0.056 & 0.013 \\
\hline Creatinine $(\mathrm{mg} / \mathrm{dL})$ & $0.77(0.42-2.02)$ & $0.77(0.37-1.13)$ & $0.84(0.38-1.63)$ & 0.13 & 0.44 \\
\hline \multicolumn{6}{|c|}{ Nerve conduction study (median nerve) } \\
\hline CMAP amplitude (mV) & $5.3(0-12.8)$ & $6.2(0-14.1)$ & $8.2(0-4.6)$ & 0.31 & 0.0005 \\
\hline Motor conduction velocity $(\mathrm{m} / \mathrm{s})$ & $32(17-48)$ & $39(20-50)$ & $39(20-50)$ & 0.19 & 0.008 \\
\hline
\end{tabular}

at 6 months post treatment (HR=12.81; 95\% CI 2.691 to 90.96; $\mathrm{p}=0.0001$, figure 2). These findings suggest that suppression of serum VEGF levels to within the normal range at 6 months post treatment may prolong relapsefree survival. All of the seven patients with relapsed disease were treated with thalidomide. The complete remission rate did not differ significantly between the two groups.

\section{VEGF reduction and clinical improvement}

Significant clinical and laboratory improvement could not be detected at 6 months post treatment. However, at 12 months multiple clinical and laboratory parameters significantly improved (table 2). The extent of improvement in grip strength, serum albumin and compound muscle action potential amplitude of the median nerve were significantly greater in patients with VEGF levels $<1040 \mathrm{pg} / \mathrm{mL}$ than in patients with serum VEGF $\geq 1040 \mathrm{pg} / \mathrm{mL}$ at 6 months post treatment (figure 3). In addition, rate of decrease over the first 6 months post treatment was correlated with the extent of clinical and laboratory improvements at 12 months (figure 4). These findings suggest that significant clinical and laboratory improvement can be obtained several months after VEGF levels decrease, and that the greater the decrease by 6 months post treatment, the greater the delayed improvement in laboratory findings and clinical outcome. No significant correlations between decreases in VEGF and improvement in performance status, overall neuropathy limitation scale, pleural effusion or creatinine could be detected.

\section{DISCUSSION}

We show that serum VEGF levels decreased and reached a plateau over the 6 months following treatment of peripheral blood stem cell transplantation or thalidomide. Patients with normal VEGF levels at 6 months post treatment showed significantly longer relapse-free survival and greater delayed clinical and laboratory improvements. The rate of reduction in serum VEGF over the first 6 months after treatment correlated with the extent of clinical and laboratory improvement at 12 months. These findings suggest that the extent of reduction in VEGF correlates with improvement of the disease and treatments for POEMS syndrome should aim to decrease serum VEGF within the normal range. In addition, the fact that decreased serum VEGF reached a plateau over 6 months after treatment indicates that at least 6 months are required to determine the effect of treatment, and a change in therapeutic strategy should be considered if VEGF levels do not decrease sufficiently at 6 months post treatment. This is the first study to demonstrate that serum VEGF level can be used as a surrogate biomarker to monitor disease activity and predict clinical outcome of POEMS syndrome. A reliable early predictive marker of long-term outcome will facilitate clinical trials for POEMS syndrome treatment given the inherent difficulty in larger scale prospective studies for such rare and severe diseases.

Since the first demonstration of elevated serum VEGF levels in POEMS syndrome patients, ${ }^{7}$ numerous studies have confirmed that VEGF levels increase in untreated POEMS syndrome and decrease after treatment, implicating elevated VEGF in disease pathophysiology. ${ }^{14-19}$ Indeed, the physiological effects of VEGF, such as vascular hyperpermeability and angiogenesis, ${ }^{6}$ are consistent with the characteristic symptoms of POEMS syndrome (eg, pleural effusion, oedema or angiomata). However, whether lower VEGF levels after treatment represent suppression of the disease itself or a mere epiphenomenon had not been unequivocally demonstrated. The present study clearly shows that the extent of the decreases in VEGF reflects later clinical improvement; a greater reduction at 6 months post treatment predicts better prognosis at 1 year. Moreover, if VEGF levels are suppressed below the upper limit of the normal range, longer remission can be achieved. Therefore, treatment for POEMS should aim to control VEGF within the 

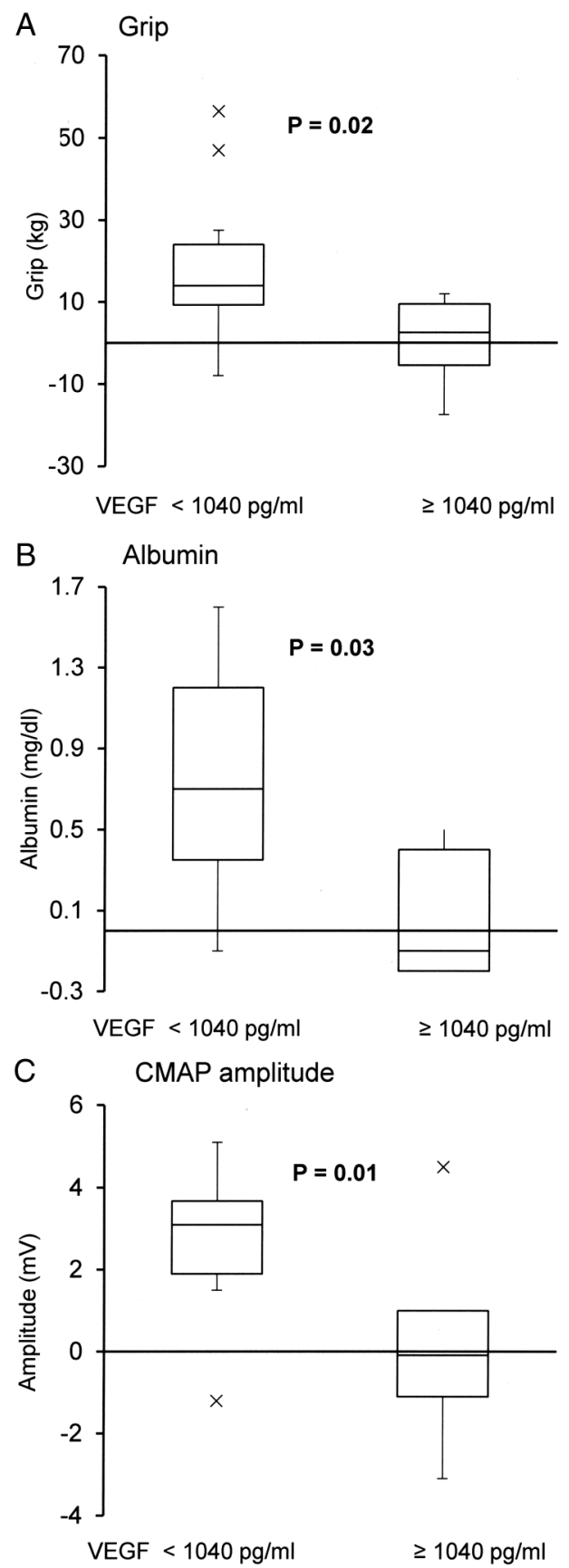

Figure 3 Changes in clinical or laboratory measures at 12 months post treatment. (A) Grip strength. (B) Serum albumin. (C) Compound muscle action potential (CMAP) amplitude of the median nerve. Patients with serum vascular endothelial growth factor (VEGF) $<1040 \mathrm{pg} / \mathrm{mL}$ at 6 months after treatment showed significant improvements in all parameters compared with patients with VEGF $\geq 1040 \mathrm{pg} / \mathrm{mL}$.

normal range. These findings strongly suggest that overproduction of VEGF plays a central role in the pathophysiology of POEMS syndrome.

This retrospective study has several limitations. First, we retrospectively investigated a small number of patients with POEMS with different backgrounds. The difference in mean age of the two groups of studied patients (transplanted and thalidomide treated) may
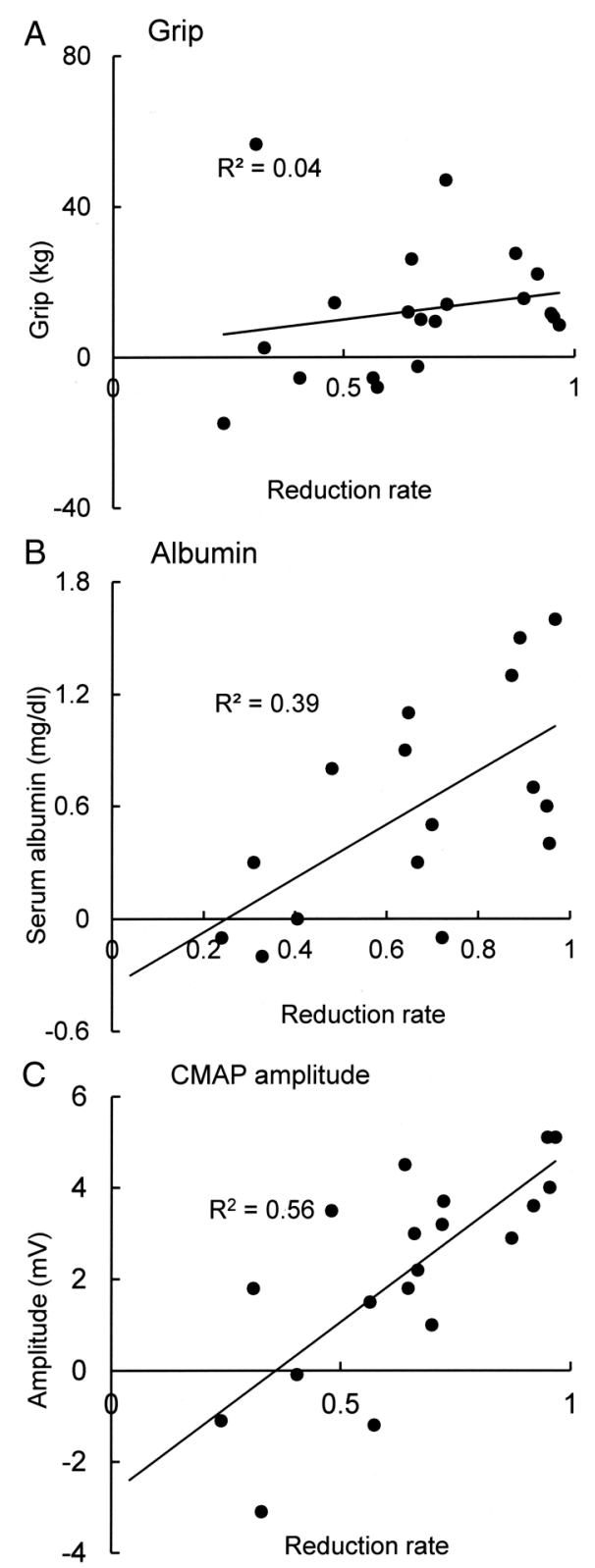

Figure 4 Correlation between reduction rate of vascular endothelial growth factor (VEGF) at 6 months after treatment and changes in grip strength $(A)$, serum albumin $(B)$, and CMAP amplitude of the median nerve $(C)$ at 12 months after treatment. The grater the rate of VEGF decline at 6 months of treatment, the better the clinical and laboratory findings at 12 months.

substantially influence treatment response and VEGF level. However, we aimed to study whether VEGF could be used as a predictive marker, irrespective of the patients' background and treatment modality. We believe that this was achieved by our data. Second, we investigated whether only serum VEGF levels reflect disease activity and prognosis of POEMS syndrome, or whether other proinflammatory cytokines, such as TNF- $\alpha$, IL-6 and IL-12, are also upregulated during active disease and IL-12 levels decrease after treatment. ${ }^{21}$ 
Inhibition of VEGF alone by a monoclonal antibody (bevacizumab) does not appear to be effective, particularly in advanced cases, ${ }^{22-24}$ further implicating other proinflammatory factors in disease progression. Future prospective studies are necessary to investigate which cytokines are most appropriate for monitoring disease activity. Third, the present study evaluated serum levels of VEGF, and it is controversial whether serum or plasma VEGF is a better indicator of disease activity. ${ }^{11} 1725$ While plasma level of VEGF is less affected by platelets, serum VEGF levels can be reflected from the serous and platelet compartments. Since the origin of VEGF in POEMS syndrome has not yet been clarified, VEGF stored in platelets may play an important role in the pathophysiology of POEMS syndrome. Therefore, we consider that monitoring serum VEGF may better indicate the total amount of VEGF in the patient. ${ }^{26}$ However, further investigations may be required to evaluate the relationship between serum and plasma VEGF levels in the treatment course of POEMS syndrome.

The prognosis for patients with POEMS syndrome was very poor when only corticosteroids were available as treatments. ${ }^{3}{ }^{4}$ However, a number of case series and reports have demonstrated improved prognosis using treatments originally developed for multiple myeloma. ${ }^{12} 14151819$ The next step is to perform well designed prospective clinical trials and establish evidence-based therapeutic guidelines. ${ }^{12}{ }^{13}$ To confirm the efficacy of a therapeutic intervention, so-called hard endpoints are expected, such as overall survival or progression-free survival. However, such studies take several years and require large sample sizes, ${ }^{11}{ }^{27}$ and are generally not feasible for rare diseases. Surrogate endpoints to assess therapeutic efficacy in a brief period could allow short-term clinical trials involving smaller patient groups. This study demonstrates that serum VEGF at 6 months post treatment can be used as a primary endpoint for POEMS syndrome treatment outcome. In addition, VEGF is suitable for an endpoint of clinical trials from the view point that VEGF measurement is quantitative and objective and can be blinded by measurement at a central laboratory.

Additional agents for multiple myeloma, such as proteasome inhibitors, monoclonal antibodies, cell cycle specific drugs, deacetylase inhibitors and signalling transduction pathway inhibitors will be available in the near future ${ }^{28}$ and could be applied to POEMS syndrome. ${ }^{13}$ While the adequacy of serum VEGF as a surrogate endpoint needs further confirmation, this marker may facilitate prospective clinical trials on the safety and efficacy of these newer drugs despite the rarity of this syndrome. In fact, we are now conducting a multicentre, double-blind and randomised controlled clinical trial ${ }^{29}$ to evaluate the efficacy and safety of thalidomide for POEMS syndrome using the rate of VEGF decrease over 6 months post treatment as the primary endpoint (declared and registered to the Japan Pharmaceuticals and Medical Devices Agency).
Contributors SM and YS analysed the data. SM, YS, KK, HH and SK designed the research, collected and wrote the manuscript. SS, MB, FN, KS YS, YI, KW, HA, CO, MT, ES and CN assisted in data collection and manuscript preparation. All authors approved the final draft of the paper.

Funding This study is supported in part by a Research Grant from the Ministry of Education, Culture, Sports, Science, and Technology of Japan (SM, Kakenhi 23790975).

Competing interests SM is funded by a Grant-in-Aid for Scientific Research from the Ministry of Education, Culture, Sports, Science and Technology of Japan. SK is funded by Grants-in-Aid for Scientific Research from the Ministry of Education, Culture, Sports, Science and Technology of Japan and a Grant-in-Aid for Scientific Research from the Ministry of Health, Labour, and Welfare of Japan, and served as Associate Editor of Journal of Neurology, Neurosurgery, and Psychiatry, and as an Editorial Board member of Journal of the Neurological Sciences.

Ethics approval The protocol was approved by the institutional review board of Chiba University Graduate School of Medicine.

Provenance and peer review Not commissioned; internally peer reviewed

Data sharing statement No additional data are available.

Open Access This is an Open Access article distributed in accordance with the Creative Commons Attribution Non Commercial (CC BY-NC 4.0) license, which permits others to distribute, remix, adapt, build upon this work noncommercially, and license their derivative works on different terms, provided the original work is properly cited and the use is non-commercial. See: http:// creativecommons.org/licenses/by-nc/4.0/

\section{REFERENCES}

1. Bardwick PA, Zvaifler NJ, Gill GN, et al. Plasma cell dyscrasia with polyneuropathy, organomegaly, endocrinopathy, M protein, and skin changes: the POEMS syndrome. Report on two cases and a review of the literature. Medicine 1980;59:311-22.

2. Arimura K, Hashiguchi T. Crow-Fukase syndrome: clinical features, pathogenesis and treatment in Japan. In: Yamamura T, Kira J, Tabira T, eds. Current Topics in Neuroimmunology. 2007:241-5.

3. Nakanishi T, Sobue I, Toyokura Y, et al. The Crow-Fukase syndrome: a study of 102 cases in Japan. Neurology 1984:34:712-20.

4. Kuwabara S, Hattori T, Shimoe $\mathrm{Y}$, et al. Long term melphalan-prednisolone chemotherapy for POEMS syndrome. J Neurol Neurosurg Psychiatry 1997;63:385-7.

5. Isose S, Misawa S, Kanai K, et al. POEMS syndrome with GuillanBarre syndrome-like acute onset: a case report and review of neurological progression in 30 cases. J Neurol Neurosurg Psychiatry 2011;82:678-80.

6. Dvorak HF, Brown LF, Detmar M, et al. Vascular permeability factor/ vascular endothelial growth factor, microvascular hyperpermeability, and angiogenesis. Am J Pathol 1995;146:1029-39.

7. Watanabe O, Arimura K, Kitajima I, et al. Greatly raised vascular endothelial growth factor (VEGF) in POEMS syndrome. Lancet 1996;347:702

8. Soubrier MJ, Dubost JJ, Sauvezie BJ. POEMS syndrome: a study of 25 cases and a review of the literature. French Study Group on POEMS Syndrome. Am J Med 1994;97:543-53.

9. Watanabe O, Maruyama I, Arimura K, et al. Overproduction of vascular endothelial growth factor/vascular permeability factor is causative in Crow-Fukase (POEMS) syndrome. Muscle Nerve 1998;21:1390-7.

10. Nobile-Orazio E, Terenghi F, Giannotta C, et al. Serum VEGF levels in POEMS syndrome and in immune-mediated neuropathies. Neurology 2009;72:1024-6.

11. Dispenzieri A. POEMS syndrome: update on diagnosis, risk-stratification, and management. Am J Hematol 2012;87:804-14.

12. Kuwabara S, Dispenzieri A, Arimura $\mathrm{K}$, et al. Treatment for POEMS (polyneuropathy, organomegaly, endocrinopathy, M-protein, and skin changes) syndrome. Cochrane Database Syst Rev 2012;6: CD006828.

13. Misawa S, Kuwabara S. Polyneuropathy, organomegaly, endocrinopathy, monoclonal gammopathy and skin changes (CrowFukase) syndrome: diagnostic criteria and treatment perspectives POEMS syndrome. Clin Exp Neuroimmunol 2013;4:318-25. 
14. Kuwabara S, Misawa S, Kanai K, et al. Autologous peripheral blood stem cell transplantation for POEMS syndrome. Neurology 2006;66:105-7.

15. Kuwabara S, Misawa S, Kanai K, et al. Thalidomide reduces serum VEGF levels and improves peripheral neuropathy in POEMS syndrome. J Neurol Neurosurg Psychiatry 2008;79:1255-7.

16. Kuwabara S, Misawa S, Kanai K, et al. Neurologic improvement after peripheral blood stem cell transplantation in POEMS syndrome. Neurology 2008;71:1691-5.

17. D'Souza A, Hayman SR, Buadi F, et al. The utility of plasma vascular endothelial growth factor levels in the diagnosis and follow-up of patients with POEMS syndrome. Blood 2011:118:4663-5.

18. Dispenzieri A, Moreno-Aspitia A, Suarez GA, et al. Peripheral blood stem cell transplantation in 16 patients with POEMS syndrome, and a review of the literature. Blood 2004;104:3400-7.

19. Dispenzieri A, Klein CJ, Mauermann ML. Lenalidomide therapy in a patient with POEMS syndrome. Blood 2007;110:1075-6.

20. Rajkumar SV, Harousseau JL, Durie B, et al., International Myeloma Workshop Consensus Panel 1. Consensus recommendations for the uniform reporting of clinical trials: report of the International Myeloma Workshop Consensus Panel 1. Blood 2011;117:4691-5.

21. Kanai K, Sawai S, Sogawa K, et al. Markedly upregulated serum interleukin-12 as a novel biomarker in POEMS syndrome. Neurology 2012;79:575-82.
22. Straume O, Bergheim J, Ernst P. Bevacizumab therapy for POEMS syndrome. Blood 2006;107:4972-3.

23. Samaras P, Bauer S, Stenner-Liewen F, et al. Treatment of POEMS syndrome with bevacizumab. Haematologica 2007:92:1438-9.

24. Sekiguchi $\mathrm{Y}$, Misawa S, Shibuya K, et al. Ambiguous effects of anti-VEGF monoclonal antibody (bevacizumab) for POEMS syndrome. J Neurol Neurosurg Psychiatry 2013;84:1346-8.

25. Tokashiki T, Hashiguchi T, Arimura K, et al. Predictive value of serial platelet count and VEGF determination for the management of DIC in the Crow-Fukase (POEMS) syndrome. Intern Med 2003;42:1240-3.

26. Hashiguchi T, Arimura K, Matsumuro K, et al. Highly concentrated vascular endothelial growth factor in platelets in Crow-Fukase syndrome. Muscle Nerve 2000;23:1051-6.

27. Dispenzieri A, Kyle RA, Lacy MQ, et al. POEMS syndrome: definitions and long-term outcome. Blood 2003;101:2496-506.

28. Ocio EM, Richardson PG, Rajkumar SV, et al. New drugs and novel mechanisms of action in multiple myeloma in 2013: a report from the International Myeloma Working Group (IMWG). Leukemia 2014;28:525-42.

29. Katayama K, Misawa S, Sato Y, et al. Japanese POEMS syndrome with Thalidomide (J-POST) Trial: study protocol for a phase II/III multicentre, randomised, double-blind, placebo-controlled trial. BMJ Open 2015;5:e007330 